\title{
Integração Ferroviária Sul-Americana: Por Que Não Anda Esse Trem?*
}

Ivanil Nunes $^{* *}$

Resumo: Considerando-se que, no presente, a integração da infra-estrutura dos mais variados modais é uma tendência irreversível torna-se relevante entender o papel das ferrovias nos fluxos de comércio e de pessoas que circulam na Região, principalmente, a partir do momento em que a integração econômica sul-americana parece se consolidar. A relevância da análise encontra-se no fato de que 0 funcionamento de modais de transportes, ou a existência de modais de transportes eficientes, podem ser determinantes para a ampliação das vantagens comparativas e competitivas em determinados setores econômicos dos páses sul-americanos, bem como um fator motivador aos fluxos, tanto de pessoas quanto de comércio, entre esses países.

Palavras-chave: Integração, Ferrovia, Comércio, Infra-estrutura, Transporte.

Abstract: Being considered that, in the present, the integration of the infrastructure of the most varied modal is an irreversible tendency becomes relevant to understand the paper of the railroads in the trade flows and of people that circulate in the Area, mainly, starting from the moment in that the South American economical integration seems if it consolidates. The relevance of the analysis is in the fact that the operation of modal of transports, or the existence of modal of efficient transports, they can be decisive for the enlargement of the comparative and competitive advantages in certain economical sections of the South American countries, as well as a positive factor to the flows, as much of people as of trade, among those countries.

Keywords: Integration, Railroad, Trade, Infrastructure, Transport.

\footnotetext{
* Trabalho apresentado no $1^{\underline{a}}$ Congresso Latino-Americano de História Econômica e 4a. Jornadas Uruguaias de História Econômica. Montevidéu: 5, 6 e 7 de dezembro de 2007. As reflexões contidas neste artigo estão contempladas na Tese de doutoramento, em fase de conclusão, junto ao Programa de Integração da América Latina (PROLAM/USP).

** Doutorando do Programa de Pós-Graduação em Integração da América Latina - PROLAM/USP. E-mail: ivanilnunes@ usp.br. Recebido em 11/07/07 e aceito em 04/12/07.
} 


\section{Introdução}

A temática sobre a integração regional não é recente. Diversos projetos originários de governos ou de agências multilaterais já foram elaborados na Regiâo visando o propósito de integração regional; porém, desde o final da década de 1940, com as formulaçóes iniciais da Comissão Econômica para a América Latina e o Caribe (CEPAL), o assunto parece tornar-se bastante imperativo entre os meios acadêmicos, agências multilaterais e instâncias governamentais. A criação da Associação Latino-Americana de Livre Comércio (ALALC), em 1960, parece contemplar parte desta ação política, acadêmica e estatal de integração econômica regional debatida desde o final da Segunda Guerra Mundial. Este processo de integração econômica na América do Sul que possui, portanto, pelo menos meio século de vigência é marcado por considerável aumento de circulação de pessoas e mercadorias no âmbito intra-regional. No entanto, a maior parte das mercadorias que circulam regionalmente são transportadas fora da área de fronteira. Assim, o aumento dos fluxos comerciais regionais, ampliados após as implementaçóes desse acordo e principalmente a partir da década de 1990, não provocou acréscimo proporcional de integração entre as regióes dos países em que havia efetiva comunicação física por modais terrestres, tais como o ferroviário e rodoviário.

O objetivo neste trabalho é analisar o porquê de a infra-estrutura ferroviária sul-americana ser tão pouco integrada.

Considera-se neste trabalho que a inexpressiva participação ferroviária no processo de integração regional está relacionada ao tipo de desenvolvimento econômico e social realizados historicamente pelos países da Região. Assim, se por um lado, as ferrovias sul-americanas contribuíram, e contribuem, ao processo de integração econômica por outro essa contribuição aconteceu somente em alguns dos espaços econômicos dos países da região, cuja predominância estavam e estão direcionados à produção exportadora de matérias-primas; as ferrovias sul-americanas contribuíram, até meados do século XX, para a integração intra-nacional e inter-regional: seja através da expansão de linhas férreas em âmbito nacional quanto pela construção de conexôes internacionais, que serviram para aumentar a possibilidade de trânsito nacional e inter-regional do transporte de passageiros, de mercadorias, 
animais ou pequenas expediçóes, na Região. Porém, a partir de 1955, observase uma verdadeira "operação-desmonte" que foi desarticulando-nas desta função de integrarem a Regiáo tanto em relação ao espaço intra-nacional quanto inter-regional ${ }^{1}$.

A analise sobre os motivos da construção de uma infra-estrutura ferroviária na América do Sul tão pouco integrada regionalmente poderá contribuir para o entendimento sobre como a integração econômica da América do Sul vem ocorrendo ao longo dos últimos dois séculos, tanto em âmbito internacional, quanto em âmbito nacional e intra-regional; principalmente, se levarmos em conta que esta pouca integração física parece ser uma das conseqüências do tipo de desenvolvimento econômico e social implantados, desde o século XIX, nos países da Região. O principal problema consiste em buscar entender porquê a participação do modal ferroviário na América do Sul é praticamente inexistente no processo de integração dos fluxos de comércio e de pessoas que circulam regionalmente, apesar das fortes evidências de expressivo aumento do comércio tanto no âmbito mundial quanto regional, ocorrido particularmente a partir da abertura econômica da década de 1990.

\section{Sobre a infra-estrutura ferroviária na América do Sul}

As ferrovias estão presentes em todos os países sul-americanos. Sete desses países, possuem conexóes internacionais que formam a infraestrutura ferroviária internacional que possibilita a ligação ferroviária entre os seguintes países: Chile-Peru, Bolívia-Chile, Bolívia-Peru, Bolívia-Brasil, Argentina-Bolívia, Argentina-Chile, Argentina-Brasil, Argentina-Paraguai, Brasil-Uruguai, Brasil-Paraguai. A Argentina, a Bolívia e o Brasil se conectam com quatro países fronteiriços, cada, e são os que mais possuem conexóes internacionais com seus vizinhos; seguidos de Chile, que possui conexóes ferroviárias internacionais com três de seus vizinhos; Peru e Paraguai, respectivamente, possuem ligaçóes férreas com dois países vizinhos; o Uruguai através de uma conexão está ligado, pela via férrea, apenas com o Brasil. Formam, portanto, ampla rede férrea de $74.715 \mathrm{~km}$ de extensão distribuída pelos países citados: Argentina, com 30.818 km, Bolívia com 4.200 km,

\footnotetext{
${ }^{1}$ Sobre este "desmonte" recomenda-se a leitura de Paula (2000) e Nunes (2005).
} 
Brasil com 29.605 km, Chile com 5.034 km, Paraguai com 441 km, Peru com $1.720 \mathrm{~km}$ e Uruguai com 2.897 de vias férreas (ASSOCIACIÓN LATINOAMERICANA DE FERROCARRILES, 2006).

Essas malhas férreas foram construídas a partir de meados do século XIX para atender, dentre os principais propósitos, ao escoamento de mercadorias em direção ao (ou proveniente dos) portos. Em função desse motivo observase que a maior parte da infra-estrutura ferroviária pouco parece contribuir, no presente, com a integração econômica regional em curso, ainda que tenha ocorrido na América do Sul consistente aumento da quantidade de circulação de mercadorias, nas últimas décadas.

A extensão da malha ferroviária sul-americana atingiu seu auge por volta de meados da década de 1950, quando passou a sofrer processo de encampação pública, seguido de desativação de linhas (ramais ou mesmo pequenas ferrovias inteiras, após 1960), que por diversos motivos não conseguiram mais competir com outros modais, como rodoviários, dutoviários, ou mesmo marítimo, no qual há séculos se baseiam os transportes externos realizados entre os diversos países da Região. Quando se compara a extensão das linhas desativadas na Região, entre 1945 e 2006, percebe que essa redução chegou a atingir a pouco mais de um quarto do total instalado:

Quadro 1 - América do Sul. Extensão das linhas férreas (1945-2006); em km

\begin{tabular}{|c|c|c|c|c|}
\hline País & Extensão & Extensão & Extensáo & Extensáo \\
\hline & linhas em 1945 & linhas em 1960 & das linhas 2006 & $\begin{array}{c}\text { diferença }(\mathrm{em} \%) \\
2006-1960\end{array}$ \\
\hline Argentina & 42.578 & 43.923 & 30.818 & 29,8 \\
\hline Bolívia & 2.343 & 3.470 & 4.200 & 21,0 \\
\hline Brasil & 35.280 & 38.339 & 29.605 & 22,8 \\
\hline Chile & 8.188 & 8.685 & 5.034 & 42,0 \\
\hline Colômbia & 3.064 & 3.562 & 2.030 & 43,0 \\
\hline Peru & 2.875 & 2.934 & 1.720 & 41,4 \\
\hline Uruguai & 3.005 & 2.982 & 2.897 & 2,9 \\
\hline Total & 97.333 & 103.895 & 76.304 & 26,6 \\
\hline
\end{tabular}

FONTE: CEPAL, 1965, p. 5-6; ALAF, 2006

Observa-se que, após a década de 1960, embora tenha ocorrido desativação de diversas linhas férreas também ocorreu considerável aumento dos fluxos de comércios entre os países sul-americanos. Em 1960, a totalidade das 
exportaçóes da América Latina atingiu a 212.934.000 toneladas enquanto as importaçóes equivaliam a 41.234.000 toneladas. Dessa soma dos fluxos comerciais internacionais, no entanto, se observa que as exportaçóes representavam, 84\% do comércio internacional dos países sul-americanos, o que significava que a maior parte destes fluxos de exportaçóes e importaçóes ocorriam para fora e de fora, respectivamente, da Região.

Apenas uma pequena parcela das exportaçóes sul-americanas, de 15.970.000 de toneladas (7\%), dirigia-se para a própria América do Sul e México, e, das importaçóes totais, 14.875 .000 de toneladas (29\%) eram provenientes dessa mesma Região (CEPAL, 1965, p. 152). Dentre os principais países exportadores da Região, em 1960, abaixo destacados, percebe-se que a Argentina foi o que, em toneladas, mais exportou para os demais países da América do Sul; o Brasil, naquele ano, que exportou intraregião apenas a metade do total realizado pelos argentinos despontou, em quantidade, como maior importador regional.

Tabela 1 - América do Sul. Principais países exportadores (1960; em ton.)

\begin{tabular}{|l|c|c|c|c|c|c|}
\hline \multicolumn{1}{|c|}{ Países } & \multicolumn{3}{|c|}{ Exportaçóes } & \multicolumn{3}{c|}{ Importaçóes } \\
& totais & $\begin{array}{c}\text { América do } \\
\text { Sul }\end{array}$ & \% do total & totais & $\begin{array}{c}\text { América do } \\
\text { Sul }\end{array}$ & $\%$ do total \\
\hline Brasil & 10.607 .900 & 1.095 .300 & 10,3 & 15.608 .800 & 6.034 .100 & 38,7 \\
\hline Argentina & 9.371 .000 & 2.067 .500 & 22,1 & 10.599 .200 & 5.617 .576 & 53,0 \\
\hline Chile & 7.047 .500 & 480.900 & 6,8 & 3.239 .700 & 387.100 & 11,9 \\
\hline
\end{tabular}

FONTE: CEPAL, 1965

Já o Chile, dentre os três, é o que menos realizou transportes intra-região. Os dois países maiores exportadores, indicados na Tabela 1, acima, têm em comum o fato de importarem, naquele momento, maior quantidade de mercadorias provenientes da América do Sul, em relação às quantidades por eles exportadas para esta Região. Vale lembrar que isso gera uma situação em que alguns dos meios de transportes utilizados para o tráfego dessas mercadorias, sejam eles vagóes, caminhóes ou dutos passam a ser utilizados mais no sentido da importação que da exportação realizada por esses três países.

Conforme se verifica na Tabela 2, abaixo, esse montante de circulação intra-regional de mercadorias cresceu consideravelmente a partir da década de 1960 . 
Tabela 2 - Brasil. Variação das exportaçóes e importaçóes (1960-2005)

\begin{tabular}{|l|c|c|c|c|c|c|c|}
\hline & \multicolumn{4}{|c|}{$\begin{array}{c}\text { Anos escolhidos (em milhóes de } \\
\text { toneladas) }\end{array}$} & \multicolumn{3}{c|}{ Ano base 1960=100 } \\
\hline Brasil & $\mathbf{1 9 6 0}$ & $\mathbf{1 9 9 0}$ & $\mathbf{2 0 0 0}$ & $\mathbf{2 0 0 5}$ & $\mathbf{1 9 9 0}$ & $\mathbf{2 0 0 0}$ & $\mathbf{2 0 0 5}$ \\
\hline Exportaçóes totais & 10,6 & 168,1 & 244,6 & 397,0 & $1.584,6$ & $2.306,1$ & $3.742,1$ \\
\hline Importaçóes totais & 15,6 & 57,2 & 92,8 & 93,6 & 366,4 & 594,4 & 599,7 \\
\hline Export. América do Sul & 1,1 & 7,2 & 14,4 & 21,4 & 657,5 & $1.318,7$ & $1.949,7$ \\
\hline Import. América do Sul & 6,0 & 8,3 & 32,9 & 25,4 & 137,6 & 545,4 & 421,2 \\
\hline
\end{tabular}

FONTE: CEPAL, 1965; Brasil, 2006

Tomando-se a economia brasileira como referência, percebe-se que as exportaçóes totais cresceram mais de 3.700\%, entre 1960 e 2005; em relaçáo às exportaçóes para a América do Sul, este montante chegou a crescer quase $2.000 \%$. Já as importaçóes totais, brasileiras, cresceram aproximadamente 600\%, enquanto as importaçóes originárias da América do Sul aumentaram pouco acima de $400 \%$, no mesmo período.

Num primeiro momento se poderia supor que o acréscimo dos fluxos comerciais na América do Sul, ocorridos a partir da década de 1960 e notadamente após a década de 1990, implicasse em aumento proporcional de maior circulação terrestre de pessoas e mercadorias, pelo menos entre as localidades de países em que houvesse efetiva comunicação física. E que isso provocasse também em ampliação do uso de modais terrestres tais como o ferroviário e o rodoviário, (ainda que pudesse se considerar como "aceitável" que houvesse maior participação, na quantidade transportada, através do modal marítimo, uma vez que a maior parte dessas transaçóes comerciais ocorreram com mercados localizados fora da região).

No entanto, ao longo das últimas décadas este aumento de circulação de mercadorias não ocorreu, proporcionalmente, através das vias férreas, o que parece indicar dificuldades em se realizar a integração física entre os países da região através deste modal, que já fora bastante utilizado nas transaçóes comerciais, conforme se pode observar na Tabela 3. 
Tabela 3 - América do Sul. Principais fluxos de comércio via modal ferroviário (1965); em toneladas

\begin{tabular}{|l|c|c|c|c|c|c|}
\multicolumn{1}{|c|}{ Países } & Exportaçáo & $\begin{array}{c}\text { por } \\
\text { ferrovia }\end{array}$ & $\begin{array}{c}\text { \% (do } \\
\text { total) }\end{array}$ & Importaçáo & $\begin{array}{c}\text { por } \\
\text { ferrovia }\end{array}$ & $\begin{array}{c}\text { \%(do } \\
\text { total) }\end{array}$ \\
\hline Chile - Bolívia & 5.020 & 5.020 & 100,0 & 13.083 & 10.200 & 78,0 \\
\hline Brasil-Bolívia & 8.510 & 5.446 & 64,0 & 20.508 & 15.920 & 77,6 \\
\hline Brasil - Uruguai & 101.198 & 44.020 & 43,5 & 103.267 & 26.200 & 25,4 \\
\hline Argentina - Bolívia & 47.768 & 15.450 & 32,3 & 71.196 & 3.444 & 4,8 \\
\hline Argentina - Chile & 199.156 & 45.000 & 22,6 & 432.901 & 45.581 & 10,5 \\
\hline Bolívia - Peru & 1.448 & 276 & 19,1 & 2.703 & 276 & 10,2 \\
\hline Argentina - Paraguai & 166.594 & 13.820 & 8,3 & 298.633 & 14.930 & 5,0 \\
\hline Brasil - Argentina & 1.989 .345 & 8.700 & 0,4 & 1.482 .138 & 9.500 & 0,6 \\
\hline Total & 2.519 .039 & 137.732 & 5,5 & 2.424 .429 & 126.051 & 5,2 \\
\hline
\end{tabular}

FONTE: CEPAL, 1972, p. 13

Pôde-se observar que, em 1965, os principais fluxos comerciais (exportaçóes e importações) pela via ferroviária representaram pouco mais de $5 \%$ do total realizado intra-região e se localizavam entre Chile-Bolívia; BrasilBolívia; Brasil-Uruguai; Argentina-Bolívia; Argentina-Chile e Bolívia-Peru. Entre as duas principais economias da América do Sul (Brasil-Argentina), a participação da ferrovia no intercâmbio comercial era uma das menores, representando apenas $0,4 \%$ das exportaçóes brasileiras para a Argentina e $0,6 \%$ das argentinas para o Brasil. Os aumentos dos fluxos comerciais na Regiáo passam, a partir da década de 1960, a ser realizados cada vez mais através de outros modais, como, por exemplo, o duto-viário e rodoviário, além de manter-se em alta a participação do modal marítimo: mesmo entre países fronteiriços, como é o caso de Brasil e os demais países-membro do Mercosul, conforme se pode observar na Figura 1. 
Figura 1 - Brasil. Exportaçóes e importaçóes (1990 e 2005); por modais; em toneladas transportadas

\begin{tabular}{|c|c|c|c|c|c|c|c|c|c|}
\hline Brasil. Exportações para o Mercosul (por modais; em toneladas) & \multicolumn{6}{|c|}{ Brasil. Importações do Mercosul (por modais; em toneladas) } \\
\hline
\end{tabular}

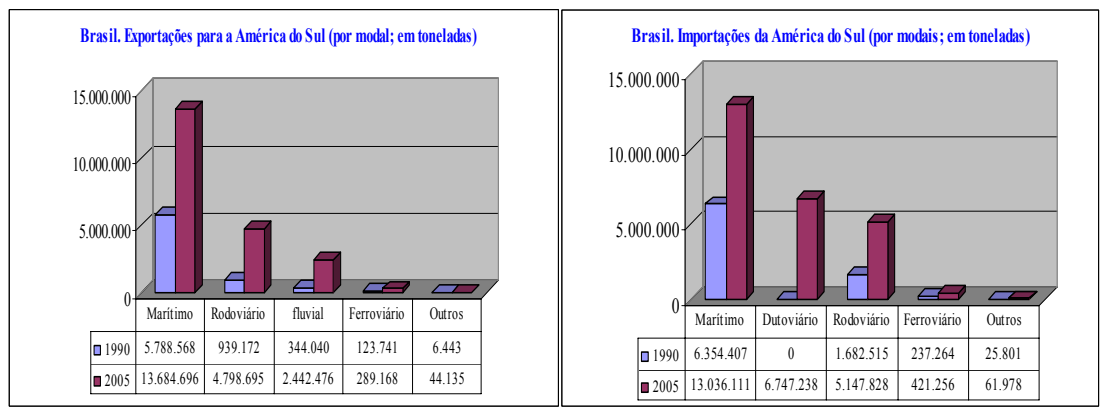

FONTE: Brasil, 2006

Especificamente sobre a utilização do modal ferroviário na Região se poderia a princípio visualizar um quadro positivo, de expansão de seu uso, se tomarmos como base a quantidade transportada pelo modal ferroviário anteriormente e compará-los com o presente (2005), ainda que, conforme indica a Tabela 3, as exportaçóes brasileiras, pela via ferroviária para a Argentina, Bolívia e Uruguai, juntos, durante o ano de 1990, equivaleu a apenas a metade da quantidade exportada por ferrovia pelo Brasil, em 1965, a estes países; quando foram exportadas 58.116 toneladas por este modal. Situação que se reverte, a partir de 1990, quando se constata que as exportaçóes brasileiras, também pela via ferroviária cresceram consideravelmente. Pois enquanto as exportaçóes brasileiras para a América do Sul foram aumentadas de 7.201.964, em 1990, para 21.354.732 de toneladas, em 2005, (acréscimo de 196,5\%), as exportaçóes para o Mercosul pelo modal ferroviário subiram de 30.782 para 386.564 toneladas, o que representou acréscimo de 1.155,8\%, no mesmo período. As importaçóes brasileiras provenientes da Argentina, 
Bolívia e Uruguai pelo modal ferroviário, tomando-se como ano-base 1965, também seguiu em crescimento, pois enquanto naquele ano elas atingiram a marca de 51.620 toneladas, em 1990 essa quantia chegou a 223.165 toneladas, e a 398.637 toneladas em 2005 - representando acréscimos de 332,3\% entre 1960 e 1990 , e de mais 78,6 \% entre 1990 e 2005 . No entanto, proporcionalmente ao total transacionado em 2005, pelo diversos modais, entre os países sul-americanos a participação do ferroviário caiu, e muito, em relação ao desempenho demonstrado por este em 1965.

Tabela 4 - Brasil. Exportaçóes e importaçóes com o Mercosul (inclusos Bolívia e Chile); 2005

\begin{tabular}{|c|c|c|c|c|c|c|c|c|c|c|}
\hline \multicolumn{11}{|c|}{ Exportaçáo (por modais, em mil toneladas) } \\
\hline & \multicolumn{2}{|c|}{ Brasil-Argentina } & \multicolumn{2}{|c|}{ Brasil-Bolívia } & \multicolumn{2}{|c|}{ Brasil-Chile } & \multicolumn{2}{|c|}{ Brasil-Paraguai } & \multicolumn{2}{|c|}{ Brasil-Uruguai } \\
\hline Modais & Expor. & $\%$ total & Expor. & $\%$ total & Expor. & $\%$ total & Expor. & $\%$ total & Expor. & $\%$ total \\
\hline marítimo & $8.030,2$ & 67,2 & 11,7 & 1,7 & $2.377,9$ & 72,3 & 95,0 & 6,1 & 177,1 & 22,6 \\
\hline rodoviário & $2.041,5$ & 17,1 & 375,9 & 53,9 & 792,6 & 24,1 & $1.006,7$ & 65,1 & 535,4 & 68,4 \\
\hline fluvial & $1.631,9$ & 13,7 & 133,4 & 19,1 & 83,1 & 2,5 & 223,6 & 14,5 & 49,0 & 6,3 \\
\hline ferroviário & 222,4 & 1,9 & 160,5 & 23,0 & 24,1 & 0,7 & 162,4 & 10,5 & 1,8 & 0,2 \\
\hline outros & 19,7 & 0,2 & 15,5 & 2,2 & 9,7 & 0,3 & 58,8 & 3,8 & 19,3 & 2,5 \\
\hline dutoviário & 0,0 & 0,0 & 0,0 & & & & & 0,0 & 0,0 & 0,0 \\
\hline Total & $11.945,6$ & 100 & 697,0 & 100 & $3.287,4$ & 100 & $1.546,5$ & 100 & 782,6 & 100 \\
\hline \multicolumn{11}{|c|}{ Importação (por modais, em mil toneladas) } \\
\hline & \multicolumn{2}{|c|}{ Brasil-Argentina } & \multicolumn{2}{|c|}{ Brasil-Bolívia } & \multicolumn{2}{|c|}{ Brasil-Chile } & \multicolumn{2}{|c|}{ Brasil-Paraguai } & \multicolumn{2}{|c|}{ Brasil-Uruguai } \\
\hline Modais & Impor. & $\%$ total & Impor. & $\%$ total & Impor. & $\%$ total & Impor. & $\%$ total & Impor. & $\%$ total \\
\hline marítimo & $8.401,2$ & 73,2 & 426,4 & 6,0 & $1.523,7$ & 88,0 & 6,5 & 0,3 & 189,3 & 20,8 \\
\hline rodoviário & $2.434,1$ & 21,2 & 51,6 & 0,7 & 206,8 & 11,9 & $1.812,6$ & 93,5 & 637,5 & 70,0 \\
\hline fluvial & 11,3 & 0,1 & 20,9 & 0,3 & 0,0 & 0,0 & 12,8 & 0,7 & 1,1 & 0,1 \\
\hline ferroviário & 216,8 & 1,9 & 22,6 & 0,3 & 0,5 & 0,0 & 100,1 & 5,2 & 81,8 & 9,0 \\
\hline outros & 199,7 & 1,7 & 1,0 & 0,0 & 1,2 & 0,1 & 7,0 & 0,4 & 0,0 & 0,0 \\
\hline dutoviário & 209,6 & 1,8 & $6.537,6$ & 92,6 & 0,0 & 0,0 & 0,0 & 0,0 & 0,5 & 0,1 \\
\hline Total & $11.472,7$ & 100 & $7.060,2$ & 100 & $1.731,7$ & 100 & $1.939,1$ & 100 & 910,3 & 100 \\
\hline
\end{tabular}

FONTE: Brasil, 2006

Tomando-se os fluxos comerciais do Brasil, com seus demais parceiros do Mercosul (incluindo-se Bolívia e Chile), percebe-se que no ano de 2005 a participação do modal ferroviário aumentou proporcionalmente nas exportações brasileiras para a Argentina, que foram ampliadas de 0,4 para $1,9 \%$ do total; no sentido importação (Argentina-Brasil) a participação do modal ferroviário cresceu de 0,6 para $1,9 \%$ das mercadorias transportadas. Em relação ao comércio boliviano e uruguaio, a queda foi enorme: os fluxos 
de comércio, pela via ferroviária Brasil-Bolívia, que representavam 64 e 77,6\% (das exportações e importaçóes brasileiras com aquele país, respectivamente), foram reduzidas para 23 e $0,3 \%$, (exportaçóes e importaçóes, respectivamente), em 2005; ano em que mais de $90 \%$ das importaçóes brasileiras provenientes da Bolívia foram realizados através do modal dutoviário; com o Uruguai, esses números (de exportaçóes e importaçóes brasileiras, respectivamente) se reduzem de 43,5 e 25,4\%, em 1965, para apenas 0,2 e 9\%, em 2005. As exportaçóes brasileiras para o conjunto desses países sul-americanos acima apontados atingem o total de 18.259.072 toneladas, das quais 571.183 toneladas foram transportadas por ferrovia, equivalentes a 3,1\% do total; das importaçóes provenientes daqueles países obtém-se a soma de 23.113.962 toneladas, das quais 421.256 toneladas entraram no Brasil pela via férrea, em 2005; o que equivalem a apenas $1,8 \%$ do total importado deste conjunto de países.

\section{Por que não anda esse trem?}

Se existem linhas férreas, ligando pelo menos sete países da América do Sul e se existem mercadorias a serem transportadas regionalmente e considerandose que efetivamente aumentaram-se às exportaçóes e importaçóes na Região porquê, então, não aconteceu aumento proporcional dos transportes pelo modal ferroviário? Parte desta resposta parece estar diretamente relacionada ao tipo de desenvolvimento econômico e social realizados historicamente pelos países da Região e a função que as ferrovias vêm desempenhando neste processo, desde o século XIX.

Durante o período colonial a inserção da América do Sul na economia internacional foi marcada por histórica subalternidade econômica, política e social, que durou aproximadamente quase três séculos. Esse tipo de integração ao sistema econômico mundial parece ter deixado marcas históricas profundas - como, por exemplo, o desenvolvimento associado à dinâmica econômica, política e social, externas. A causa principal para o fato de a malha ferroviária dos países da América do Sul pouco integrarem entre si parece estar relacionada ao tipo de desenvolvimento econômico consolidado no século XIX pela classe dominante agrário-exportadora e seus aliados. $\mathrm{O}$ fator dinâmico daquela economia tinha por base a produção ou extração de 
produtos primários, localizadas em alguns poucos espaços econômicos em detrimento de outros, que pudessem ser exportadas. Daí, a convergência dos interesses dessas classes com capitalistas externos também interessados no funcionamento neste sistema econômico e social.

Parte-se, aqui, do princípio de que durante o surgimento e, posteriormente, com a consolidação do modo de produção capitalista os espaços econômicos foram sendo construídos sob a marca de uma distinção entre países e entre regióes intra-nacionais que apesar de distintas entre si foram sendo paulatinamente integradas ao modo de produção capitalista, para o qual não se constituíam empecilhos o fato de haver diferenciadas formas de organizaçóes espaciais dentro da divisão internacional do trabalho. A construção destes vários espaços mundiais integrados, apesar de distintos entre si, faz parte da lógica da produção em escala mundial, que por sua vez, necessita tanto de uma superestrutura que lhe dê garantias para sua expansão quanto de uma infra-estrutura econômica, que possibilite a realização desta expansão. Logo, a integração econômica que está em curso na América do Sul, pelo menos desde o século XIX, em constante adaptação aos diferentes estágios do processo de acumulação, deve ser entendida como um processo contínuo de expansão e unificação de mercados seja no interior de uma nação seja em âmbito regional ou mundial. Conforme adverte Schiffer:

produzir espaço (capitalista) implica em construir ligaçóes entre as localizaçóes, de modo a propiciar uma homogeneização tal que a forma-mercadoria possa se implantar. $\mathrm{O}$ espaço é, portanto, recriado (transformado) continuamente, segundo os estágios do processo de acumulação. (SCHIFFER, 1989, p. 15).

Ao longo dos últimos cinco séculos constata-se a expansão e unificação de mercados que ocorre, em geral, do centro para a periferia: fenômeno que se observa ter ocorrido em distintas partes do mundo através de diversas formas, mas, sobretudo sob o domínio de espanhóis e portugueses, sobre a América do Sul e Central, a partir do século XVI, e dos ingleses, a partir do século XIX, que, por terem dominado vastas áreas territoriais em diversas partes do mundo, haviam montado extenso império. $\mathrm{O}$ que equivale a dizer que a expansão passou a ocorrer a partir dos países onde se originou o sistema 
capitalista para os não-capitalistas. Segundo Luxemburgo (1985), a partir do século XIX, no entanto, a busca de novos mercados acrescenta um diferencial em relação à expansão colonial européia iniciada no século XVI, pois, em função do contexto econômico e financeiro estruturados na Europa onde se dinamizava o processo de industrialização, requeria-se, do ponto de vista dos capitalistas ingleses e outros, além do controle de fontes de matériasprimas, também a conquista de novos mercados consumidores. É dentro dessa necessidade de amplos espaços econômicos que deve ser compreendido o processo de expansão e mesmo de ocupação territorial, em pleno século XIX.

Logo, os países sul-americanos, do ponto de vista da dinâmica do capital internacional, teriam sido "apenas" mais uma dentre outras tantas regióes do mundo que passaram a disputar ou serem disputadas pelos capitais externos que visavam investimentos em serviços públicos, ferrovias e outros. Ao se inserirem, não o fazem de modo regionalmente uniforme, ou de modo a beneficiar todas as classes sociais ou o conjunto da economia nacional; ao se abrir uma linha de exportação, seja de produtos agrícolas, de minérios ou outra mercadoria isso se dá em algumas poucas localidades que passam a necessitar de infra-estruturas que potencializem a integração dessas localidades "inseridas" ao centro econômico próprio da nação, ou externo a ela: em geral externo à Região. O processo de inclusão de cada uma dessas localidades, que vão sendo construídas dentro da lógica de expansão capitalista requer, a cada instante, infra-estruturas que potencializem a produtividade do sistema.

É dentro dessa lógica, e somente a partir do momento em que a produção atinge o ponto de equilíbrio que viabiliza o negócio e, por conseqüência, a possibilidade de retorno financeiro dos capitais aplicados, é que a tração animal, da mula, passa a ser substituída pela ferrovia. Ainda que pareça uma obviedade vale atentar para o fato de que essa criação do espaço econômico não é estático, o que impóe a cada um desses espaços a contínua transformação, segundo cada estágio. Assim, o formato da infra-estrutura, ou, melhor dizendo, o modal implantado em cada momento histórico está relacionado às exigências desta elite (classe ou fração de classe) que o implanta, e não à lógica da racionalidade da integração dos diversos espaços nacionais. Vale observar que essa clareza de propósitos de classe não deve 
ser entendida como resultante de uma concepção clássica de classe, advinda do sistema de produção capitalista europeu - em que a classe se estabelece em função da universalização da propriedade privada, fundamentada pela racionalidade do direito e representativa de um Estado nacional. Segundo Fernandes (1981, p. 33) na América Latina as classes sociais hegemônicas se caracterizam pela sua situação econômica, pela sua capacidade de condicionar direta e indiretamente tanto os processos de concentração social e riqueza, do prestígio social e do poder (inclusive o poder de monopolizar o controle do poder do Estado e suas funções) "quanto os mecanismos societários de mobilidade, estabilidade e mudanças sociais".

Existe, portanto, uma característica peculiar no processo de formação da classe hegemônica instauradora do sistema agrário-exportador da Região.

Na América Latina, o capitalismo e a sociedade de classes não são produtos de uma evoluçáo interna o que, em si mesmo, não constitui a maior fonte de problema. Acresce que, até o presente, o capitalismo evoluiu na América Latina sem contar com as condiçôes de crescimento autosustentado e de desenvolvimento autônomo. Em conseqüência, classes e relações de classes carecem de dinamismos societários que são essenciais para a integração, a estabilidade e as transformaçôes equilibradas da ordem social inerente à sociedade de classes (FERNANDES, 1981, p. $35)$.

Assim, no interior de cada uma das naçóes sul-americanas formaramse distintos espaços econômicos, ocupados pelas diferentes elites locais que competem entre si buscando lograr a hegemonia política e econômica em âmbito nacional. Do ponto de vista político a hegemonia, em geral, vem acompanhada da possibilidade de o grupo, que se instala no aparelho do Estado utilizar-se do recurso de impor-se como legítimo representante dos interesses "supremos da nação", ao defender propositadamente seus interesses, que são da fração de classe, como sendo nacionais. Do ponto de vista econômico a hegemonia confere a este seleto grupo a exploraçáo de fatores de produção disponíveis como terra, trabalho e capital que passam a deslocar-se para essas áreas o que facilita a manutenção do domínio político da respectiva fração da classe dominante, ou de seus aliados. É essa 
consciência de seus interesses, não isentas de conflitos no interior da classe dominante, que possibilita que a concentração de riqueza e prestígio social se converta em poder político institucional capaz de comandar o controle do Estado - que representa, dentre outras, as relaçóes existentes entre o poder político e o econômico.

Portanto, ao se criar uma linha de exportação essa fração da classe dominante o faz visando à integração econômica de "seu" espaço econômico restrito, podendo este espaço ser mais ou menos dinâmico, do ponto de vista do conjunto da economia nacional, em função do tipo de mercadoria ofertada. Essa especialização exportadora, de algumas regióes dentro desses países parece, no entanto, definir certas características quanto ao tipo de desenvolvimento da infra-estrutura ferroviária implementada no século XIX: regionalmente excludente e vinculada a alguns poucos clientes e produtos; características ainda presentes no traçado ferroviário regional, em pleno século XXI. Nas localidades em que se estabeleceu a produção de produtos agrícolas, deu-se o uso extensivo de terras assim como a grande quantidade transportada criou a demanda por infra-estrutura de transporte que precisou levar em consideração, além do porto exportador, o próprio mercado interno - em que na maioria dos casos, ambas localizaçóes (do porto e do mercado interno) se coincidiam, como é o caso do Rio de Janeiro, no Brasil, Buenos Aires, na Argentina, Montevideo, no Uruguai.

Já nas localidades que se inseriram através da extração de minerais o modelo de desenvolvimento acabou por gerar um pólo de desenvolvimento que se comportava como um sistema econômico à parte à nação. Pois, apesar de elevada densidade de capital e avanço tecnológico, neste caso utiliza-se a uma pequena quantidade de mão-de-obra, além de a extração de minérios pouco se vincular a economia interna. Desse modo a infra-estrutura criada para servir as indústrias mineiras de exportação tornaram-se escassas ou nulas para a implementação ou ampliação do mercado interno; segundo Furtado,

as potencialidades como fator dinâmico somente se tornaram conhecidas quando o Estado interferiu para obrigar essas empresas a adquirir dentro do país parte de seus insumos para captar, sob a forma de impostos, uma parte significativa do fluxo de renda que tradicionalmente era remetido ao estrangeiro (FURTADO, 1970, p. 65). 
Para essas elites e seus aliados de classe, o fato de a integração logística ferroviária, em pleno século XXI, pouco atender a integração nacional ou inter-regional parece não se constituir em sério problema uma vez que as ferrovias sul-americanas continuaram, tais quais desde o século XIX, a atender algumas poucas localidades ligando-as aos portos.

As ferrovias surgiram como parte da ocupação do espaço econômico no âmbito das naçóes - em pleno desenvolvimento do modelo exportador (e expatriador), logo, fazem parte da estrutura econômica e social do século XIX e foram instituídas para atenderem a propósitos específicos. A forma como as empresas ferroviárias foram sendo constituídas, construídas e operadas regionalmente exibe fartos exemplos da utilização de uso do dinheiro público por parte de seleto grupo de investidores nacionais e estrangeiros (em boa parte, ingleses) aliados a fornecedores de equipamentos, construtores e governos. Gómez e Schvarzer (2006) apesar de reconhecerem a importância que teve a criação da primeira ferrovia Argentina, a Ferrocarril del Oeste, decisiva para o desenvolvimento posterior das demais linhas férreas do país, descrevem o farto aproveitamento especulativo em torno deste tipo de empreendimento:

a maximização dos ganhos passava então pela possessão das terras que se estava por valorizar e pelo controle das operaçóes de compra de equipamentos e instalaçóes. A experiência da construção dos primeiros quilômetros de vias, que se fez brotar ganhos fabulosos aos proprietários de terras, dos contratados para realizar as obras e outros definiu os lineamentos do processo massivo do avanço ferroviário no século XIX. Durante várias décadas (...) a FCO, primeira ferrovia nacional (privada, depois estatal e em seguida estrangeira), era uma espécie de casca dos negócios fenomenais que se faziam em seu entorno e que beneficiavam a um amplo grupo de operadores ao mesmo tempo em que impulsionava a economia nacional. (GÓMEZ, SCHVARZER, 2006, p. 257).

Até mesmo a criação de conexôes ferroviárias internacionais, que uniram diversas fronteiras regionais, parecem ter sido estabelecidas visando bem pouco aos propósitos da aproximação dos povos da Região. Uma breve análise revela que esses pontos de intercâmbios internacionais ferroviários 
surgiram mais em função de conflitos do que de efetivamente integração econômica regional. As quatro primeiras conexóes internacionais acabaram se constituindo em função da Guerra do Pacífico (1879-1883). A primeira conexão surgiu quando parte do território (Arica) em que operava a Ferrocarril Tacna-Arica, construída em 1856, passou do domínio peruano para chileno. Em função da mesma guerra parte do território boliviano que compreendia o deserto de Atacama, que o ligava ao oceano Pacífico, na região de Antofagasta, foi conquistado pelo Chile, fechando-se assim, definitivamente, o acesso da Bolívia ao Pacífico. Essa necessidade estratégica boliviana, de reconstruir uma saída para o mar estimulou a criação de pelo menos mais três intercâmbios ferroviários internacionais na região, envolvendo territórios deste país, entre 1883 e 1915: conexão entre o território boliviano a Arica e Antofagasta (ambos, chilenos, após 1883), e, Mollendo, em território peruano (CEPAL, 1972, p. 128-129). Pelo menos outras duas alternativas foram realizadas buscando-se vencer o isolamento a que estava submetido o território boliviano: o convênio assinado entre a Bolívia e Argentina, em 1894, que procurava criar a uma alternativa de ligação ferroviária dos Andes bolivianos com o norte argentino através da construção de um ramal que partisse das linhas da Ferrocarril Central Norte, até Villazón, na fronteira com a Bolívia, cuja execução das obras, efetivamente, somente se concretizou em 1924; e o convênio celebrado em 1906, também entre Argentina e Bolívia, em que se iniciou lento processo de negociação para se construir uma outra ligação férrea que pudesse ligar a Planície boliviana aos portos de Rosário e Buenos Aires, através da malha ferroviária do norte argentino. Projeto realizado somente em dezembro de 1957 e seguido de uma interrupção das linhas no ano seguinte, devido à destruição de pontes causadas pelas chuvas; a operação das linhas retomou-se somente em novembro de 1965 (CEPAL, 1972, p. 138-139).

A segunda etapa de construções de conexóes internacionais ferroviárias tem como elemento central as disputas por hegemonia havidas entre Brasil e Argentina. Após a guerra contra o Paraguai (1864-1870), este país abriu o Rio Paraguai à livre navegação, o que incorreu na transformação de Corumbá em importante ponto comercial internacional com vinculação direta com o porto de Buenos Aires - num momento em que tanto Brasil, quanto Argentina e 
Chile disputavam abertamente a influência sobre os países menores da região. Neste jogo de influências, o Estado do Mato Grosso (Brasil) ficava, segundo Queiroz (2004), bastante exposto à “cobiça” estrangeira. A dificuldade de se chegar do Rio de Janeiro ao Mato-grosso, por via terrestre, em função dos vários pantanais a serem atravessados, impunha a viagem àquela localidade, a necessidade a de se passar pelo Rio da Prata, e deste, atingir aos Rios Paraná e Paraguai (QUEIROZ, 2004, p. 115). A ligação, de São Paulo (Bauru) ao Mato Grosso, se concluiu com inauguração da E. F. Noroeste do Brasil (NOB), construída entre 1905-1914, ainda que de forma incompleta, uma vez que a ponta dos trilhos permaneceu em Porto Esperança (Mato Grosso), desde a inauguração, até 1952, quando se abriu a estação de Corumbá ao tráfego, em 15 de dezembro de 1952 (BRASIL, 1960, p. 133).

Outras iniciativas brasileiras passaram a estender as linhas em direção aos demais países vizinhos. Em 1873, o governo brasileiro decidiu pela construção de uma linha férrea ligando Porto Alegre a Uruguaiana (fronteira com a Argentina) e a Santana do Livramento (fronteira com o Uruguai), que se concluíram em 1907 e 1910, respectivamente (CEPAL, 1972, p. 136); em 1931, inaugura-se à estação de Jaguarão, consolidando-se, assim, mais uma ligação férrea entre Brasil e Uruguai (BRASIL, 1960, p. 279).

O Paraguai, logo após o término da Guerra contra ele, em 1870, restabeleceu relação viária primeiro com a Argentina, através da navegação fluvial, e posteriormente através da construção de via férrea ligando Asunción a Encarnación, margem direita do Rio Paraná, divisa com a cidade argentina de Posadas. Em 1911, a ferrovia paraguaia, passou por processo de troca de bitolas, de 1,676 para 1,435 metro, para atender ao propósito de se conectar a ferrovia argentina. Em 1913, essa ligação ferroviária argentino-paraguaia se concretizou após a assinatura de acordo sobre o tráfego de pessoas e mercadorias (CEPAL, 1972, p. 138). Com o Brasil, a ligação veio a ocorrer somente com o término da construção do Ramal de férreo de Ponta-Porã, que partindo da estação de Indubrasil, localizada no km 857 da Noroeste do Brasil, atingiu a fronteira paraguaia em 19/04/1953 (BRASIL, 1960, p. 134).

Novos projetos de ligações internacionais ferroviárias se viabilizaram após a Guerra do Chaco (1933-35) em que conflitaram o Paraguai e a Bolívia. 
O prolongamento da linha férrea de denominada Ferrovia Brasil-Bolívia (Corumbá a Santa Cruz de la Sierra), ganhou novo impulso após a assinatura do Tratado de vinculação ferroviária de 25 de fevereiro de 1938, em que o governo brasileiro se comprometia em participar da realização daquele empreendimento. Vale lembrar que, o projeto de construção de uma ferrovia em território boliviano, por parte do governo brasileiro, era discutido desde o Tratado de Petrópolis ${ }^{2}$, de 1903 (CEPAL, 1972, p. 141), porém, a mudança da localidade desta via férrea, iniciada em 1939 e concluída somente em 1954, atendia a nova conjuntura econômica do pós-ciclo da borracha, descrito por Figueiredo.

a Noroeste do Brasil e a Brasil-Bolívia pela sua localização geográfica podem, em breve ser um eixo de irradiação de pan-americanismo, pois a elas ficarão ligadas as capitais do Peru, do Chile, do Paraguai, da Argentina, do Uruguai e do Brasil (...) (FIGUEIREDO, 1950, p. 95).

Outras duas conexões internacionais férreas foram estabelecidas entre os territórios argentino e chileno: a primeira, entre o trecho de Mendoza (Argentina) a Los Andes (Chile), inaugurado em 1910, após 23 anos de construção, e o segundo ligando Salta a Antofagasta, inaugurado em 1948.

Segundo a CEPAL (1972, p. 8-9), no início da década de 1960, estavam em operação pelo menos 13 pontos de intercâmbios internacionais ferroviários; destes, nove eram operados por ferrovias que possuíam o mesmo padrão de bitolas o que possibilitava inclusive o intercâmbio de material rodante.

\footnotetext{
${ }^{2}$ Tratado firmado entre Brasil e Bolívia, em 1903, pelo qual o Brasil adquiriu o Acre e indenizou a Bolívia, em dinheiro, além de ceder terras no Mato Grosso e comprometer-se a construir a Estrada de Ferro Madeira-Mamoré para escoar a produção boliviana pelo rio Amazonas.
} 
Quadro 2 - América do Sul: Pontos de intercâmbios internacionais ferroviários

\begin{tabular}{|c|c|c|c|}
\hline Rotas & Conexão & Ferrovias & bitola (m) \\
\hline $\begin{array}{l}\text { Arica (Chile) } \\
\text { La Paz Bolívia) }\end{array}$ & $\begin{array}{l}\text { Visviri } \\
\text { Viacha }\end{array}$ & $\begin{array}{c}\text { F C Arica La Paz } \\
\text { Empresa Nacional de F. de } \\
\text { Bolívia }\end{array}$ & $\begin{array}{l}1,0 \\
1,0\end{array}$ \\
\hline $\begin{array}{l}\text { Antofagasta (Chile) } \\
\text { La Paz (Bolívia) }\end{array}$ & Olague (Chile) & $\begin{array}{l}\text { F. C. Antofagasta-Bolívia } \\
\text { Empresa Nacional de F. de } \\
\text { Bolívia }\end{array}$ & $\begin{array}{l}1,0 \\
1,0\end{array}$ \\
\hline $\begin{array}{l}\text { Maratani (Peru) } \\
\text { La Paz (Bolívia) }\end{array}$ & $\begin{array}{l}\text { Punio } \\
\text { Guaqui }\end{array}$ & $\begin{array}{c}\text { F. C Del Sur Del Perú } \\
\text { Empresa Nacional de F. de } \\
\text { Bolívia }\end{array}$ & $\begin{array}{l}1,4 \\
1,0\end{array}$ \\
\hline $\begin{array}{c}\text { Arica (Chile) - Tacna } \\
\text { (Peru) }\end{array}$ & Arica & F. C Tacna-Arica & 1,4 \\
\hline $\begin{array}{c}\text { Buenos Aires (Arg.) } \\
\text { Santiago (Chile) }\end{array}$ & $\begin{array}{l}\text { Las Cuevas } \\
\text { Caracoles }\end{array}$ & $\begin{array}{c}\text { F. C. Gral. Belgrano } \\
\text { F. F Transandino por Juncal }\end{array}$ & $\begin{array}{l}1,0 \\
1,0\end{array}$ \\
\hline $\begin{array}{l}\text { Buenos Aires (Arg.) } \\
\text { Antofagasta (Chile) }\end{array}$ & $\begin{array}{l}\text { Socompa (Arg.) } \\
\text { Socompa (Chile) }\end{array}$ & $\begin{array}{c}\text { F. C. Gral. Belgrano } \\
\text { F. F Transandino por Socompa }\end{array}$ & $\begin{array}{l}1,0 \\
1,0\end{array}$ \\
\hline $\begin{array}{c}\text { Buenos Aires (Arg.) } \\
\text { La Paz (Bolívia) }\end{array}$ & $\begin{array}{c}\text { La Quiaca } \\
\text { Atocha }\end{array}$ & $\begin{array}{c}\text { F. C. Gral. Belgrano } \\
\text { Empresa Nacional de F. de } \\
\text { Bolívia }\end{array}$ & $\begin{array}{l}1,0 \\
1,0\end{array}$ \\
\hline $\begin{array}{l}\text { Buenos Aires (Arg.) } \\
\text { Santa Cruz (Bolívia) }\end{array}$ & $\begin{array}{l}\text { Pocitos } \\
\text { Yacuiba }\end{array}$ & $\begin{array}{c}\text { F. C. Gral. Belgrano } \\
\text { Empresa Nacional de F. de } \\
\text { Bolívia }\end{array}$ & $\begin{array}{l}1,0 \\
1,0\end{array}$ \\
\hline $\begin{array}{l}\text { São Paulo (Brasil) } \\
\text { Santa Cruz (Bolívia) }\end{array}$ & $\begin{array}{l}\text { Corumbá } \\
\text { Arroyo Concepción }\end{array}$ & $\begin{array}{c}\text { E. F. Noroeste do Brasil } \\
\text { Empresa Nacional de F. de } \\
\text { Bolívia }\end{array}$ & $\begin{array}{l}1,0 \\
1,0\end{array}$ \\
\hline $\begin{array}{l}\text { Buenos Aires (Arg.) } \\
\text { Sáo Paulo (Brasil) }\end{array}$ & $\begin{array}{l}\text { Paso de los Libres } \\
\text { Uruguaiana }\end{array}$ & $\begin{array}{l}\text { F. C. Gral. Urquiza } \\
\text { V. F. Rio Grande do Sul }\end{array}$ & $\begin{array}{l}1,4 \\
1,0\end{array}$ \\
\hline $\begin{array}{l}\text { Buenos Aires (Arg.) } \\
\text { Assunción (Paraguai) }\end{array}$ & $\begin{array}{c}\text { Posadas } \\
\text { Encarnación }\end{array}$ & $\begin{array}{c}\text { F. C. Gral. Urquiza } \\
\text { F. C. Pres. Carlos A. Lopez }\end{array}$ & $\begin{array}{l}1,4 \\
1,4\end{array}$ \\
\hline $\begin{array}{c}\text { São Paulo (Brasil) } \\
\text { Montevideo } \\
\text { (Uruguai) }\end{array}$ & $\begin{array}{l}\text { Livramento } \\
\text { Rivera }\end{array}$ & $\begin{array}{l}\text { V. F. Rio Grande do Sul } \\
\text { F. C. del Estado del Uruguay }\end{array}$ & $\begin{array}{l}1,0 \\
1,4\end{array}$ \\
\hline $\begin{array}{l}\text { São Paulo (Brasil) } \\
\text { Montevideo } \\
\text { (Uruguai) }\end{array}$ & $\begin{array}{l}\text { Jaguarão } \\
\text { Rio Branco }\end{array}$ & $\begin{array}{l}\text { V. F. Rio Grande do Sul } \\
\text { F. C. del Estado del Uruguay }\end{array}$ & $\begin{array}{l}1,0 \\
1,4\end{array}$ \\
\hline
\end{tabular}

FONTE: CEPAL, 1972

Em quatro destes pontos haveria, no entanto, necessidade de transbordos: no trecho entre Maratani (Peru) e La Paz (Bolívia); entre o Rio Grande do Sul (Brasil) com a Argentina (Uruguaiana - Paso de los Libres) e nos dois 
trechos entre este mesmo Estado brasileiro e Montevideo (Uruguai), tanto pela via Livramento-Rivera quanto pela Jaguarão-Rio Branco.

A construção desta infra-estrutura foi interrompida, porém, por diversos fatores que atravancaram a utilização do modal ferroviário como alternativa ao transporte marítimo na Região. Segundo a CEPAL, um dos motivos desta interrupção à expansão ferroviária internacional está relacionado à nacionalização das ferrovias, ocorridas após a Segunda Guerra. Na Argentina, em 1948, no Uruguai, em 1949, no Brasil, em 1957, o processo estaria relacionado por um conjunto de transaçóes financeiras destinadas a descongelar as divisas acumuladas com o Reino Unido durante a Segunda Guerra Mundial.

Um resultado imediato da nacionalização foi a necessidade de programar a recuperação da infra-estrutura e equipamentos, muito descuidados durante a guerra e completar e integrar as redes ferroviárias, começando pelas linhas nacionais mais importantes e deixando para mais tarde os trechos internacionais. (CEPAL, 1972, p. 131).

Se por um lado é inegável que as ferrovias sul-americanas contribuíram muitíssimo e contribuem ao processo de integração econômica, por outro, esse processo esteve, basicamente, limitado a alguns espaços econômicos dos países da região, cuja predominância estavam e estão direcionados à produção exportadora de matérias-primas. O que se observa, a partir de 1950, na Região, é que essas ferrovias foram deixando, ao longo dos anos, de cumprir as funçóes a elas peculiares, como por exemplo, o transporte de passageiros, de animais, de pequenas expediçóes, dentre outros serviços, para tornarem-se cada vez mais especializadas nos transportes de cargas. É fato que de meados do século XIX até por volta de 1950 elas facilitaram o processo de integração intra-nacional dos países da Região através da expansão de linhas férreas em âmbito nacional, bem como contribuíram para os primeiros passos da integração inter-regional sul-americana por meio da construção de conexôes internacionais, que durante décadas atenderam, intra-região, aos transportes de passageiros, de mercadorias, animais ou pequenas expediçóes, e sobretudo, integraram diversas localidades intra-nacionais ao mercado mundial e aos centros econômicos nacionais, através de linhas que, na maioria das vezes, 
têm como sentido, quase único, os portos.

Importante notar que a tentativa de integração das linhas férreas entre os países da região estavam presente desde as primeiras instalaçóes, que datam de meados do século XIX. Assim, este propósito já aparecia entre as metas dos projetos mais ambiciosos realizados na Região apesar do visível domínio do modal marítimo na circulação de pessoas e mercadorias ser evidente, pelo menos até por volta de 1940. Antes, porém, de se consolidarem como mecanismo efetivo no processo de integração, essas conexóes férreas passaram a enfrentar a concorrência dos outros modais, que a partir da década de 1950, passaram a se materializar, também, como alternativa ao transporte marítimo e fluvial, como é o caso dos modais dutos-viários, aéreo, e, principalmente, rodoviário: aparentemente mais flexíveis ao atendimento da circulação de mercadorias diversas, que passaram a ter maiores demandas, tanto internamente quanto regionalmente. Essas alteraçóes de funçóes das empresas férreas que, a partir da década de 1950 passaram por uma verdadeira operação-desmonte, tornaram-nas, na prática, opçóes de transportes de segunda categoria.

\section{Considerações finais}

O formato dessa rede férrea, que pouco integra regionalmente, revela, portanto, um dos principais aspectos do desenvolvimento econômico e social sul-americano marcado pela vinculação com o "de fora" em detrimento da efetiva integração intra-regional o que torna evidente que a interdependência entre amplos setores econômicos locais, exportadores de matérias-primas, com os interesses externos não é um fenômeno restrito ao século XIX; logo, essa "vinculação" externa não se limita a um estágio específico da história econômica regional, como, por exemplo, o período compreendido entre meados do século XIX e a Crise de 1929, pois tal como ocorria, desde as primeiras implantações, as ferrovias sul-americanas continuam a atender no presente, quase que privativamente a seleto grupo de proprietários de mercadorias exportáveis.

A ação de construção ou re-construção desta infra-estrutura não é estática. Altera-se ao longo do tempo em função da capacidade política desses grupos sociais hegemônicos e de seus aliados em implementar projetos 
de infra-estrutura que atendam aos seus interesses de classes. Logo, se a infraestrutura é resultado do modelo de desenvolvimento econômico e social, pode-se aferir que esta é modificada, por volta de meados do século XX, para atender às novas demandas advindas com a produção econômica regional que, conforme se observa no Quadro 3, amplia a participação de produtos industrializados na formação dos PIB regionais.

Quadro 3 - América do Sul. Participação da produção industrial no PIB (1940-1955; em \%)

\begin{tabular}{|l|c|c|c|}
\hline \multicolumn{1}{|c|}{ País } & $\mathbf{1 9 4 0}$ & $\mathbf{1 9 5 0}$ & $\mathbf{1 9 5 5}$ \\
\hline Argentina & 23 & 24 & 25 \\
\hline Chile & 18 & 23 & 23 \\
\hline Uruguai & 18 & 20 & 23 \\
\hline Equador & 16 & 16 & 15 \\
\hline Brasil & 15 & 21 & 23 \\
\hline Venezuela & 14 & 11 & 13 \\
\hline Peru & 13 & 14 & 15 \\
\hline Colômbia & 8 & 14 & 15 \\
\hline
\end{tabular}

FONTE: Bethell, 2005, p. 32, p. 106

Verifica-se, portanto, enorme aumento da participação dos setores vinculados ao espaço urbano e industrial no processo decisório destes diversos países; se durante a implementação da industrialização (de substituição de importaçóes), entre 1914-1945 essa nova elite necessitou da aliança com os trabalhadores para enfrentar a hegemonia política dos setores agrários, a partir da década de 1950, a disputa da hegemonia política se desloca para o campo da burguesia industrial e de suas fraçóes de classe (pequena burguesia nacional; associada ao capital externo, e, além disso, a própria burguesia internacional que se "internaliza" nas principais economias da América Latina). Esses novos interesses hegemônicos impóem transformações na organização do espaço econômico, que foi sendo alterado para contemplar, a partir de entấo, às demandas da circulação também no âmbito do mercado interno e inter-regional; não mais a uma circulação voltada basicamente em direção (ou proveniente do) porto, mas direcionada a diversos pontos de produção, distribuição e consumo; pontos esses espalhados em vasto espaço econômico. 
Depreende-se daí, que as ações estatais de integração ocorridas pósmeados da década de 1950 atendiam também aos propósitos da ampliação dos mercados tanto para as indústrias nacionais instaladas no período 191445 quanto para o atendimento da demanda logística das multinacionais instaladas na América do Sul após a Segunda Guerra Mundial. Pois, a participação das manufaturas se torna crescente tanto nas exportaçóes totais quanto para dentro da própria área da ALALC, a partir de 1960.

Tabela 5 - América do Sul. Participaçáo das manufaturas no comércio: total e intra-região (1960-1990)

\begin{tabular}{|l|c|c|c|c|c|c|c|c|}
\hline & \multicolumn{2}{|c}{1960} & \multicolumn{2}{c|}{$\mathbf{1 9 7 0}$} & \multicolumn{2}{c|}{$\mathbf{1 9 8 0}$} & \multicolumn{2}{c|}{1990} \\
\hline & total & $\begin{array}{c}\text { intra- } \\
\text { regiāo }\end{array}$ & total & $\begin{array}{c}\text { intra- } \\
\text { região }\end{array}$ & total & $\begin{array}{c}\text { intra- } \\
\text { região }\end{array}$ & total & $\begin{array}{c}\text { intra- } \\
\text { região }\end{array}$ \\
\hline ALADI & 3,4 & 10,6 & 9,8 & 33,4 & 17,3 & 46,1 & 33,0 & 51,3 \\
\hline Argentina & 4,1 & 6,6 & 14,2 & 33,0 & 23,2 & 43,7 & 29,3 & 45,3 \\
\hline Brasil & 2,2 & 8,4 & 13,2 & 47,3 & 37,2 & 79,9 & 51,8 & 82,9 \\
\hline
\end{tabular}

FONTE: Bethell, 2005, p. 191

Parece configurar-se, a partir da Segunda Guerra Mundial, e particularmente após a criação da ALALC (renomeada, em 1980, para Asociación Latinoamericana de Integración - ALADI), um cenário de ampliação do comércio de manufaturas, tanto interna quanto externamente à Regiáo. No conjunto, os países sul-americanos tiveram suas exportaçóes de manufaturas ampliadas de 3,4\% do total, em 1960, para mais de um terço do total destas, em 1990; Argentina e Brasil, no mesmo período passaram de 4,1 e $8,4 \%$ para 29,3 e 51,8\%, respectivamente. No âmbito da intra-regiáo sul-americana, as exportaçóes de manufaturas cresceram, proporcionalmente, ainda mais em relação ao total das exportaçóes, ampliando-se de 10,6\%, em 1960, para 51,3\%, em 1990. As indústrias localizadas no Brasil parecem ter sido, de longe, as que mais conseguiram ampliar seus mercados intraregionais, uma vez que a participação das exportaçóes das manufaturas produzidas no Brasil, que em 1960 representavam apenas 8,4\% do total exportado à Região ampliou-se para $82,9 \%$ das exportaçóes brasileiras para os demais países da ALADI.

Considerando-se que as açóes dos Estados buscam garantir a reprodução ampliada do capital e não se comportam apenas como instrumento de uma 
classe específica; ainda que em diversos momentos essas açôes tomem a aparência de contradição com os interesses de setores da classe dominante, pode-se aferir que a expansão da logística de transportes terrestres na Região, baseadas na opção rodoviária nada possui de contraditória. A ação estatal, de se re-construir a rede de transportes através da construçáo de rodovias ou re-capacitação da rede férrea existente anteriormente e, por conseqüência, ao provocar o desmonte de parcela do sistema de transportes ferroviários foi o que, de fato, possibilitou o aumento da racionalidade do conjunto da economia - tornando-a mais competitiva e produtiva seja para a parcela da elite pertencente à burguesia industrial, que passou a contar com maior espaço homogeneizado para sua reprodução, seja para os setores agrárioexportadores, que passaram a contar com ferrovias cada vez mais direcionadas para uso quase exclusivo aos transportes deste seleto grupo de exportadores de mercadorias que há séculos fluem através do sistema ferroviário-portuário da Região.

A indústria automobilística, em particular, que passou a expandir-se devido ao uso intensivo de automóveis, caminhóes e ônibus, em estradas cada vez mais modernas, torna-se beneficiária direta das açóes estatais de diversos países da Regiáo, que a partir da década de 1950 passaram a re-inventar o modo de circulação para atender às demandas inerentes da crescente produção industrial. Esse aumento da produçâo industrial além de alterar o modelo de circulação de mercadorias no âmbito interno de cada um dos países sul-americanos modifica também o fluxo de comércio em âmbito regional, uma vez que as participaçóes das manufaturas passam a crescer tanto em relação às exportaçóes totais quanto intra-região.

É, portanto, com base nos propósitos de uma estratégia de reconstrução da logística rodoviária, inserida no contexto da industrialização que deve ser entendida a verdadeira "operação-desmonte" do modal ferroviário sul-americano, a partir da década de 1950; quando parece encerrar-se a possibilidade de integração tanto em âmbito nacional, quanto inter-regional, através do modal ferroviário. Assim, as ferrovias que operam nesta Região, no século XXI, parecem ter passado a desempenhar funçóes ainda mais restritas quando comparadas com o modelo de negócios desempenhado por elas entre meados do século XIX e meados do século XX. No século XXI 
as ferrovias sul-americanas parecem ter voltado a cumprir como principal função àquela semelhante que estimulou a implantação delas no início do século XIX: a de modal de uso quase privativo ao atendimento de seleta classe de exportadores cuja pauta, de mercadorias transportadas, é composta por reduzido grupo de produtos, dentre os quais pouquíssimo se incluem os transportes interurbanos de passageiros e não mais, principalmente após a década de 1990, os de passageiros internacionais, de animais, de pequenas expediçóes, ou outros serviços não menos importantes, anteriormente oferecidos por estas empresas férreas.

A partir do processo de re-concessão ocorrida na década de 1990, observase que na maior parte das empresas ferroviárias dos países sul-americanos, sobreveio à implantação de um modelo de operação em que o transporte de passageiros foi praticamente erradicado. O mesmo aconteceu com o transporte de "pequenas expediçóes". As ferrovias passaram a atender apenas aos seus grandes clientes - em alguns casos, como o brasileiro, percebe-se que esses grandes clientes são as mesmas empresas que adquiriram o controle acionário dessas ferrovias durante os processos de re-concessóes realizados nos países da região, na década de 1990 .

Nada restou da breve experiência de circulação, via ferroviária, de trens de passageiros entre o Brasil e seus vizinhos. Os trens internacionais da década de 1950, para Buenos Aires e Montevideo, bem como os últimos "Trens da morte” que circularam entre Bauru (São Paulo) e Bolívia, até a década de 1980, são apenas lembranças da possibilidade de viagens sobre trilhos envolvendo os passageiros dos países da região. Em relação ao transporte de mercadorias por via férrea, se observa uma quase ausência do uso desta modalidade visto que a maior parte dos fluxos comerciais ocorrem fora da zona de fronteira, por via marítima. O modal ferroviário parece continuar a cumprir o papel de mecanismo de exportação dos produtos primários - mercadorias mais adequadas ao transporte ferroviário e marítimo - cujas características principais são, além de baixo valor agregado, grandes pesos e volumes.

O devir do sistema ferroviário sul-americano é, no entanto, uma verdadeira incógnita uma vez que a perspectiva de integração em curso, a partir da década de 1990, impóe, inevitavelmente, a reconstrução de uma 
nova cadeia de logística regional que passe a funcionar sob novos conceitos - o da integração operacional entre os mais diversos modais, e recoloca em debate, portanto, um rearranjo entre ganhadores e perdedores que disputam esta nova reconstrução logística (estratégica) regional, em pleno curso. 


\section{Referências Bibliográficas}

ASSOCIACIÓN LATINOAMERICANA DE FERROCARRILES (ALAF). Atlas Ferroviario Latinoamericano. Buenos Aires: ALAF, 2006.

BALASSA, Bela A. Teoria da integração econômica. Lisboa: Livraria Clássica, 1961.

BETHELL, Leslie (Org.). A América Latina após 1930. In: História da América Latina. Tradução de Geraldo Gérson de Souza. São Paulo: Edusp, Brasília: Fundação Alexandre de Gusmão, v. VI, 2005.

BRASIL. Guia geral das estradas de ferro e empresas de transportes com elas articuladas. Rio de Janeiro: Contadoria Geral dos Transportes, 1960.

. Ministério do Desenvolvimento, Indústria e Comércio. Disponível em: http://www.aliceweb.desenvolvimento.gov.br. Acesso em: 15 set. 2006.

COMISIÓN ECONÓMICA PARAAMÉRICA LATINAY CARIBE (CEPAL). El transporte en America Latina. Nueva York: CEPAL, 1965.

. Los ferrocarrilles internacionales de Sudamerica y la integración económica regional. Nueva York: CEPAL, 1972.

FERNANDES, Florestan. Capitalismo dependente e classes sociais na América Latina. 3. ed. Rio de Janeiro: Zahar Editores, 1981.

FIGUEIREDO, José de Lima. A noroeste do Brasil e a Brasil-Bolivia. Rio de Janeiro: J. Olympio, 1950.

FURTADO, Celso. Formação econômica da América Latina. 2. ed. Rio de Janeiro, Lia, 1970.

GÓMEZ, Teresita; SCHVARZER, Jorge. La primera gran empresa de los argentinos: el Ferrocarril del Oeste (1854-1862). Buenos Aires: Fondo de Cultura Econômica, 2006.

INICIATIVA DE INTEGRAÇÃO REGIONAL SUL-AMERICANA (IIRSA). Disponível em: http://www.iirsa.org/acercadeiirsa.asp?CodIdioma=ESP. Acesso em: 10 set. 2007. 
LUXEMBURGO, Rosa. A acumulação do capital: contribuição ao estudo econômico do imperialismo. São Paulo: Nova Cultural, 1985. (Os Economistas).

NUNES, Ivanil. Douradense: a agonia de uma ferrovia. São Paulo: Annablume, 2005.

PAULA, Dilma Andrade de. Fim de linha: a extinção de ramais da Estrada de Ferro Leopoldina, 1955-1974. Niterói, 2000. Tese (Doutorado) - Departamento de História, Universidade Federal Fluminense, Rio de Janeiro.

QUEIROZ, Paulo Roberto Cimó. Uma ferrovia entre dois mundos: a E. F. Noroeste do Brasil na primeira metade do século 20. Bauru, SP: EDUSC, Campo Grande, MS: Ed. UFMS, 2004.

SCHIFFER, Sueli. As politicas nacionais e a transformação do espaço paulista: 1955-80. 1989. Tese (Doutorado) - Faculdade de Arquitetura e Urbanismo, Universidade de São Paulo, São Paulo.

THOMPSON, Ian. Integración en el sector transporte en el Cono Sur: los ferrocarriles y su contribuición al comercio internacional. Buenos Aires: Banco Interamericano de Desarrollo (BID)/Instituto para la Integración de América Latina y el Caribe (INTAL), 1997.

UNIĀO EUROPÉIA. Livro Branco. A politica européia de transportes no horizonte 2010: a hora das opçóes. Itália: Comunidades Européias, 2001. Disponível em: http://europa.eu.int. Acesso em: 10 set. 2007. 